\title{
Characterizations and rheological study of the purified polysaccharide extracted from quince seeds
}

Rezagholi, Fatemeh; Hashemi, Seyed Mohammad Bagher; Gholamhosseinpour, Aliakbar; Sherahi, Mousa Hamidabadi; Hesarinejad, Mohammad Ali; Ale, Marcel Tutor

Published in:

Journal of the Science of Food and Agriculture

Link to article, DOI:

$10.1002 /$ jsfa.9155

Publication date:

2018

Document Version

Peer reviewed version

Link back to DTU Orbit

Citation $(A P A)$ :

Rezagholi, F., Hashemi, S. M. B., Gholamhosseinpour, A., Sherahi, M. H., Hesarinejad, M. A., \& Ale, M. T. (2018). Characterizations and rheological study of the purified polysaccharide extracted from quince seeds. Journal of the Science of Food and Agriculture, 99(1), 143-151. https://doi.org/10.1002/jsfa.9155

\section{General rights}

Copyright and moral rights for the publications made accessible in the public portal are retained by the authors and/or other copyright owners and it is a condition of accessing publications that users recognise and abide by the legal requirements associated with these rights.

- Users may download and print one copy of any publication from the public portal for the purpose of private study or research.

- You may not further distribute the material or use it for any profit-making activity or commercial gain

- You may freely distribute the URL identifying the publication in the public portal 
D- glucose and 31.11\% D-mannose), $13.16 \pm 1.73 \%$ uronic acid, $5.77 \pm 0.83 \%$ moisture, $2.78 \pm 0.21$ $\%$ protein, $5.64 \pm 0.21 \%$ ash, and $0.75 \pm 0.09 \%$ fat. Our findings indicated that this gum could be introduced as a value-added by-product in the food and pharmaceutical industries. ${ }^{13} \mathrm{C}$ NMR and FT-IR suggested a highly substituted xylan structure for QSG. In dilute regime, an increase in the ion concentration was accompanied by a decrease in intrinsic viscosity of QSG. When the salt concentration increased from 0 to $50 \mathrm{mM}$, the consistency coefficient (as a measure of apparent viscosity) declined. On the other hand, with further increasing of salt concentration, the consistency coefficient (as a measure of apparent viscosity) values increased. Similarly, $G^{\prime}$ and G" values for 10 and $50 \mathrm{mM} \mathrm{CaCl}_{2}$ concentrations were less than control samples.

\section{Conclusion}

The rheological behavior of the QSG studied in this paper can provide insight into its potential application in food and pharmaceutical industries.

Keywords: Chemical composition; Chemical structure; Dilute solution properties; Dynamic rheological behavior; Quince seed gum; Steady-state properties.

\section{Introduction}

The application of hydrocolloids in food and pharmaceutical systems is enormous, notably as thickener, stabilizer, edible coating and fat replacer ${ }^{1}$. Additionally, because of their low cost and extensive functional properties, hydrocolloids are widely utilized in different applications ${ }^{2}$.

Quince is a member of the Rosaceae family, which is a native fruit of west Asian region. This fruit is widely distributed in Caucasus region, Dagestan, Afghanistan, and Antalya ${ }^{3}$. Quince seed mucilage is used in Iran to prevent asthma, relieve a cough and chest discomfort. Jouki, Mortazavi, Yazdi and Koocheki ${ }^{4}$ indicated that the optimum extraction condition of quince seed 
gum (QSG) that achieved outstanding properties with highest yield (11.58\%), antioxidant activity (29.88\%), viscosity at shear rate of $46.161 / \mathrm{s}(1473.96 \mathrm{mPa} . \mathrm{s})$, emulsion stability (94.89\%), foam stability (21.36\%) and lowest turbidity $(068 \dot{A})$ and protein content $(2.71 \%)$ were conducted with extraction temperature of $65{ }^{\circ} \mathrm{C}$, for $5 \mathrm{~min}$, and the water/seed (W/S) ratio of 25.1:1. Abbastabar, Azizi, Adnani and Abbasi ${ }^{5}$ investigated the rheological behavior of QSG and found that the flow behavior of QSG was shear thinning. The dynamic rheological measurement showed that the viscoelastic range decreased with the addition of $0.2 \mathrm{NaCl}$ solution, but elastic modulus showing an increasing trend. Dilute solution investigation demonstrated that QSG has high hydrodynamic volume, and as a result has high gelling ability in aqueous solution.

There are numerous investigations on the physicochemical and structural properties of food hydrocolloids ${ }^{6}$. The functional characteristics of biopolymers are profoundly dependent on their structural and chemical properties such as chemical composition, conformation, the sequence of monosaccharide, configuration, and position of glycoside linkage ${ }^{6}$. Therefore, it is necessary to investigate the physicochemical and structural characteristics of new sources of hydrocolloids.

In the present research, the gum from quince seeds was extracted. After purification, dilute solution behavior, steady-state and dynamic rheological properties of this gum were evaluated. Furthermore, structural properties of QSG were analyzed by carbon-13 nuclear magnetic resonance $\left({ }^{13} \mathrm{C} \mathrm{NMR}\right)$, and Fourier transform infrared spectrophotometry (FT-IR) while its monosaccharides composition was analyzed using anion exchange chromatography (HPAEC). Gel permeation chromatography (GPC) was used to investigate molecular properties of QSG such as weight average molecular weight $(\mathrm{Mw})$, number average molecular weight $(\mathrm{Mn})$, and polydispersity index (PDI). 


\section{Materials and methods}

\subsection{Extraction and Purification of polysaccharide}

Quince seed purchased from local markets in Mashhad, Iran. Quince seed gum (QSG) was extracted, at optimized conditions according to the method reported by Jouki, Mortazavi, Yazdi and Koocheki ${ }^{4}$. To purify QSG, extracted gum was dissolved in deionized water (200 rpm for $60 \mathrm{~min}$ ). The samples were then boiled in $80 \%$ ethanol to separate proteins with low molecular weight. The precipitated samples were dissolved in deionized water and stored at $4^{\circ} \mathrm{C}$ overnight to complete hydration. Any insoluble materials were removed by centrifugation at $5000 \mathrm{~g}$ for 10 min. $\mathrm{H}_{2} \mathrm{O}_{2}$ was added to the supernatant at $25{ }^{\circ} \mathrm{C}$ for $4 \mathrm{~h}$ to oxidize and remove any colored compounds. Soluble substances were again precipitated with four volumes of ethanol, freezedried and then stored in a desiccator with silica gel for further experiments.

\subsection{Analytical method}

Purification yield (\%) was determined as the dry weight of the purified gum relative to seed weight. In order to determine moisture, fat, ash and protein contents of QSG samples, recommended methods by AOAC were used ${ }^{7}$. The protein content was quantified using a factor of 6.25 (nitrogen to protein conversation factor). In order to determine total carbohydrate content in QSG samples, the phenol-sulfuric acid method was used. The uronic acid measurement was performed using the m-hydroxydiphenyl method ${ }^{8}$. 


\subsection{Monosaccharide composition}

The monosaccharide analysis was performed by a well-established procedure recommended by the National Renewable Energy Laboratory (NREL) NREL with two-step acid hydrolysis and quantified using HPAEC-PAD. In brief, ca. $30 \mathrm{mg}$ dry matter QSG material was mixed with $72 \% \mathrm{H}_{2} \mathrm{SO}_{4}$ and left to react at $30{ }^{\circ} \mathrm{C}$ for $1 \mathrm{~h}$. The reaction mixture was then diluted to $4 \% \mathrm{H}_{2} \mathrm{SO}_{4}$ and hydrolyzed in an autoclave at $120{ }^{\circ} \mathrm{C}$ for $40 \mathrm{~min}$. (Rhein-knudsen et al. 2017). HPAEC separation of the QSG was performed using an HPAEC-PAD, ICS5000 system (Dionex Corp. Sunnyvale, CA) equipped with a CarboPac ${ }^{\mathrm{TM}}$ PA1 column by a method principally as described by Arnous and Meyer ${ }^{9}$. L-fucose, L-arabinose, L-rhamnose, D-galactose, D-glucose, D-xylose, D-mannose, D-galacturonic acid, and D-glucuronic acid were used as monosaccharide standards for quantification.

\subsection{Elemental analysis}

Quantification of elements was operated using an earlier explained method ${ }^{10} .0 .5 \mathrm{~g}$ gum sample was mixed with nitric acid and hydrogen peroxide (2:1) in perfluoroalkoxy (PFA) digestion vessel. Afterward, a microwave oven was used for decomposition of the sample ( $400 \mathrm{~W}$ for 15 min). Finally, the samples were cooled to $25^{\circ} \mathrm{C}$, and the volume made up of deionized water. Mineral profile of QSG was determined using an inductively coupled plasma optical emission spectroscopy (ICP-OES) (SPECTRO ARCOS, Ametek. Germany).

\subsection{Molecular parameter measurements}


The values of Mn and Mw of QSG sample were measured by gel permeation chromatography (GPC) equipped with a PL Aquagel-OH Mixed-H column. A solution of QSG sample was prepared with deionized water and filtered through a $0.2 \mu \mathrm{m}$ filter, followed by injection at a constant flow rate of $1 \mathrm{ml} / \mathrm{min}$. The eluent water was used and monitored with refractive index detector ${ }^{1}$. For calibration, a standard curve was constructed using dextran molecular weight standards with a molecular weight between 5200 and $988,000 \mathrm{~g} / \mathrm{mol}$.

\subsection{Fourier transform infrared spectroscopy (FT-IR)}

The FT-IR spectrum of QSG sample was recorded on FT-IR spectroscopy (AVATAR 370 FTIR, Thermo Nicolet). The spectrum was obtained in a range of 400 to $4000 \mathrm{~cm}^{-1}$ at a resolution of $4 \mathrm{~cm}^{-1}$.

\section{7. ${ }^{13} \mathrm{C}$ nuclear magnetic spectroscopy (NMR)}

$5 \mathrm{mg}$ of the polysaccharide sample was dissolved in $\mathrm{D}_{2} \mathrm{O}$ with continuous stirring for $2 \mathrm{~h}$. With an Avance DRX-500 Bruker Spectrometers, equipped with a process controller, ${ }^{13} \mathrm{C}$ NMR spectra were recorded.

\subsection{Intrinsic viscosity}

A range of QSG solution was prepared from a stock solution $\left(0.3 \mathrm{~g} \mathrm{dL}^{-1}\right)$ to evaluate dilute solution properties. The measurements were carried out at $25^{\circ} \mathrm{C}$ using a capillary viscometer (KPG Ubbelohde, $\mathrm{K}=0.00753$ ). 
Kraemer, Huggins, Higiro and Tanglerpatibul and Rao are most common models used to estimate intrinsic viscosity. Therefore, these models were used to facilitate comparison of the intrinsic viscosity obtained for QSG and other natural polymers.

Kraemer model ${ }^{11}$ :

$\frac{\ln \eta_{r e l}}{C}=[\eta]+k_{k}[\eta]^{2} C$

Huggins model ${ }^{12}$ :

$\frac{\eta_{s p}}{C}=[\eta]+k_{1}[\eta]^{2} C$

where, $\mathrm{k}_{\mathrm{H}}, \mathrm{k}_{\mathrm{K}}$, and $\mathrm{C}$ are Huggins constant, Kraemer constant and solute concentrations, respectively.

Tanglertpaibul-Rao's equation ${ }^{13}$ :

$\eta_{\text {re }}=1+[\eta] \mathrm{C}$

Higiro'smodels ${ }^{14}$ :

$\eta_{r e l}=e^{[\eta] C}$

$\eta_{r e}=\frac{1}{1-[\eta] C}$

\subsubsection{Estimation of the molecular conformation}

The slope of a double logarithmic plot of specific viscosity versus concentration is a measure of polysaccharides conformation ${ }^{15,16}$. Eq. 6 was used to determine this parameter: 
$\eta_{s p}=a C^{b}$

\subsubsection{Salt tolerance $(S)$ and relative stiffness parameter $(B)$}

The intrinsic viscosity's slope at different ionic strengths versus the inverse square root of ionic strength $\left(\mathrm{I}^{-0.5}\right)$ was plotted to determine salt tolerance parameter $(\mathrm{S}){ }^{17}$ :

$[\eta]=[\eta]_{\infty}+S I^{-0.5}$

Where, $[\eta]_{\infty}$ is the intrinsic viscosity of infinite ionic strength. S parameter is a measure of chain stiffness.

Based on Smidsrød and Haug ${ }^{18}$, S parameter is notably dependent on molecular weight of the polymer. Thus, they developed a semi-emperical assay (B value method) to overcome this problem. The relative stiffness parameter (B) was quantified from the intrinsic viscosity at an ionic strength of 0.1 according to the following formula:

$\mathrm{S}=\mathrm{B}\left(\eta_{I}=0.1\right)^{v}$

In which, $v$ is usually ranged between 1.2 to 1.4 for most polyelectrolyte ${ }^{19}$. An average value of 1.3 was used in this paper.

\subsection{Steady shear measurements}

Steady shear evaluation of the gum solutions in the presence of $\mathrm{CaCl}_{2}$ was carried out by a rotational viscometer (R/S plus Rheometer) equipped with a heating circulator at $25^{\circ} \mathrm{C}$ using an SC4-18 spindle. All the measurements were performed over a wide range of shear rate from 1 to $300 s^{-1}$. 
Steady shear properties such as consistency coefficient and flow behavior index values were quantified using the power law equation:

$$
\tau=k y^{n}
$$

where $\tau$ is the shear stress $(\mathrm{Pa}), \dot{\gamma}$ is the shear rate $\left(\mathrm{s}^{-1}\right), k$ is the consistency coefficient $(\mathrm{Pa} \mathrm{s})$, and $n$ is flow behavior index (dimensionless).

\subsection{Small amplitude oscillatory shear measurements}

Dynamic rheological measurements were conducted with a HAAKE MARS III rheometer (Thermo Scientific, Karlsruhe, Germany) equipped with a Peltier plate for temperature control. Each sample was transferred onto the rheometer plate using a "parallel plate sensor" PP35/1Ti (diameter of $35 \mathrm{~mm}$ ) at the room temperature, and excess material was wiped off with a spatula. For equilibration, all samples were allowed to rest at the initial temperatures for $1 \mathrm{~min}$. The RheoWin software 3.61 (Thermo Fisher Scientific) was employed for data evaluation.

The linear viscoelastic region (LVR) was analyzed for detailed dynamic measurements to evaluate the sample's microstructure. The linear viscoelastic region (LVR) for QSG samples was determined by performing an amplitude sweep measurements $(0.01-100 \%)$ at a constant frequency $(1 \mathrm{~Hz})$ and temperature of $25^{\circ} \mathrm{C}$.

Frequency sweep tests at a constant strain in the LVR region were carried out to determine the viscoelastic nature of QSG (0.5\%). In this test, a strain of 0.5 was applied in order to disturb as less as possible the network formation. The mechanical spectra were characterized by values of $\mathrm{G}^{\prime}, \mathrm{G}^{\prime \prime}(\mathrm{Pa})$ as a function of frequency in the range of $0.01-10 \mathrm{~Hz}$ and temperature of $25^{\circ} \mathrm{C}$. The storage modulus can be used as a measure of the elastic component of the sample and similarly, the loss modulus - the viscous component of the sample. 


\subsection{Statistical analysis}

The experimental results were analyzed by one-way analysis of variance (ANOVA) using SPSS 16 (SPSS Inc., Chicago, IL). The comparison of treatment means was carried out using Duncan's multiple range test.

\section{Results and discussions}

\subsection{Chemical composition}

Chemical analysis and composition of QSG were presented in Table 1. On the average, the gum contains $85.04 \pm 2.87 \%$ carbohydrate, $13.16 \pm 1.73 \%$ uronic acid, $5.77 \pm 0.83 \%$ moisture, $2.78 \pm 0.21$ $\%$ protein, $5.64 \pm 0.21 \%$ ash, and $0.75 \pm 0.09 \%$ fat. Carbohydrates constitute the major component of the extracted QSG. Comparatively, the carbohydrate content of QSG was close to that reported for locust bean gum (85.1-88.7\%) and was more when compared to those reported for some commercial gums like guar gum $(71.1 \%)$, and gum ghatti $(78.36 \%)^{6}$.

The monosaccharide composition in Table 1 showed that xylose (40.43\% of total carbohydrates) was the primary saccharide component followed by mannose (31.11\% of total carbohydrates) with minor amounts of other monosaccharides (Table 1). The high amount of xylose and mannose in QSG composition may indicate that the structural make-up of this gum can consist of xylan and/or mannan backbone with the branching of arabinose, galactose, and glucose.

The yield of the extracted gum from quince seed was found to be $9.63 \%$, which was approximately close to that reported in the previous study $(10.9 \%)^{20}$. However, they also reported that QSG had 20.9\% protein which indicates that the purified QSG in their research has a low degree of purity. In another research, the gum was extracted from quince seed 
without purification yielding the yield value of $11.58 \%{ }^{4}$. In general, due to high carbohydrate content (85.04\%) and high level of extraction yield (9.63\%), it can be concluded that this gum is an appropriate alternative for commercial gums.

The amount of protein in the polysaccharide composition is a determinant factor in food and pharmaceutical systems. For example, several properties of gum such as a film forming capacity, emulsifying and stabilizing features as well as foaming properties are dependent on protein fraction ${ }^{6}$. Comparatively, the protein content of QSG in this study was $2.78 \%$ which is comparable to that cited for xanthan gum (2.125\%), and less than those reported for locust bean gum (5.2-7.4\%), and guar gum (8.19\%) ${ }^{21,22}$. The presence of proteins in the QSG composition reflects the ability of this biopolymer to reduce surface tension ${ }^{23}$.

Uronic acid content is an indicator of the relative degree of polyelectrolyte nature and amount of acidic polysaccharides ${ }^{24}$. The uronic acid content of QSG (13.16 \%) was less than those of flaxseed gum (21.0-25.1\%) and xanthan gum (21.5\%) and was more than those reported for gum ghatti (12.83\%), and gum Arabic (15.0\%) ${ }^{6}$. Therefore, QSG has more negative charge than ghatti and Arabic gums. Based on the previous finding, the gums with a high amount of acidic polysaccharide indicate typical Newtonian-like behavior ${ }^{21}$.

Ash content of QSG samples was found to be $5.64 \%$ which is in the range of other natural polymers. Comparatively, the ash content of QSG was more than those of locust bean gum (0.7$1.5 \%)$, Arabic gum (1.2\%) and xanthan gum (1.5\%), and was less than that of guar gum $(11.9 \%)^{21,22}$.

The results of chemical analysis observed here were different from those reported in previous research 4, 20. Different factors can influence on chemical and functional properties of hydrocolloids like source, extraction and purification processes and growing conditions ${ }^{1}$. It can 
be suggested that the purification technique applied in the current research could be the main reason for this discrepancy in chemical composition.

Mineral profile of gums can influence on some their physicochemical characteristics such as emulsifying properties (iron) ${ }^{23}$, viscosity-enhancing feature and gel-forming ability of polyelectrolyte gums $\left(\mathrm{Ca}^{+2}\right)^{25}$, and enzyme activity $\left(\mathrm{Ca}^{2+}\right.$ and $\left.\mathrm{Mg}^{2+}\right)$. Additionally, some minerals are essential for human health, whereas some of them like copper $(\mathrm{Cu})$, nickel $(\mathrm{Ni})$, lead $(\mathrm{Pb})$, cadmium $(\mathrm{Cd})$, and arsenic (As) may also have adverse effects at high concentration. Therefore, mineral composition of QSG was determined. The mineral composition of QSG is summarized in Table 1. QSG is gum with a considerable nutrient value due to the presence of high amount of calcium (7331.1 ppm), and magnesium (2632.8 ppm). Based on this result, this gum can be introduced as a value-added by-product in the food and pharmaceutical industries.

(Table 1)

\subsection{FTIR analysis}

FT-IR analysis of QSG was carried out to identify the organic functional groups in gum structure. The FT-IR analysis of QSG is consistent with the compositional analysis described above. FTIR spectrum of QSG is presented in Fig. 1, which illustrates all typical bonds and peaks characteristic of the polysaccharide. The region between below $700 \mathrm{~cm}^{-1}$ is related to the skeleton vibration of the gum with two modes consisting of angle deformation formed by heavy atoms $(\mathrm{CCO}, \mathrm{COC})$ and internal rotations around $\mathrm{CO}$ bonds ${ }^{26}$. The peaks diagnosed between 800 to $1200 \mathrm{~cm}^{-1}$ is called fingerprint or anomeric area for carbohydrates. This region is sensitive to conformational and configurational transformations of polysaccharides ${ }^{27}$ and can be used as a measure of structural differences in the various polymers. For example, Guiliano, Asia, Chatel 
and Artaud ${ }^{28}$ differentiated Acacia Senegal gum and Acacia seyal using the relative intensities of this region. The signal at $897.70 \mathrm{~cm}^{-1}$ is evidence for the presence of $\beta$-D-glycosidic linkages types of the aldopyranose in biopolymer structure ${ }^{29}$. It also suggested that the peak at $1025 \mathrm{~cm}^{-1}$ is due to the presence of uronic acid in the polysaccharide structure ${ }^{30}$. Accordingly, it can be found that QSG is a polysaccharide comprising uronic acid which was supported by the result observed for proximate analysis observed above.

The observed signals between 950 and $1200 \mathrm{~cm}^{-1}$ refer to stretching vibration of alcoholic C-O in $\mathrm{COH}$ bands in carbohydrates ${ }^{31}$. The range between $1200-1500 \mathrm{~cm}^{-1}$ results from coupling of the deformation vibrations of groups containing hydrogen atoms, namely $\mathrm{CCH}, \mathrm{HCH}, \mathrm{COH}$ and $\mathrm{HCO}^{27}$. As it can be seen in Fig. 1, these bands in this range were 1249.61, 1375.02, and $1424.40, \mathrm{~cm}^{-1}$. The peak observed at $2920 \mathrm{~cm}^{-1}$ is related to $\mathrm{C}-\mathrm{H}$ stretching, symmetric and asymmetric of the free sugar and also the vibration of symmetric stretching of $\mathrm{CH}_{2}$, indicating the existence of grafting ${ }^{32}$. This peak also could be assigned to the doubles overlapping with O$\mathrm{H}^{33}$.

The wave numbers between 3000 to $3500 \mathrm{~cm}^{-1}$ are referred to free, inter, and intramolecular bond $\mathrm{O}-\mathrm{H}$ groups ${ }^{34}$, and also reveals several properties such as free $\mathrm{O}-\mathrm{H}$ groups stretching bonds that occur in the vapor phase and bonded with hydroxyl bands in the structure of carboxylic acid ${ }^{35}$. Therefore, it can be realized that this gum contained carboxyl groups, which can act as a binding site for ions and as a result leads to improve viscous-enhancing properties and gel-forming capacity. Additionally, Sharma and Mazumdar ${ }^{36}$ stated that this broad absorbance peak is related to hydrogen bonding involving the $\mathrm{O}-\mathrm{H}$ groups of glucopyranose ring in the structure of polysaccharide chain. 


\subsection{NMR analysis}

In order to investigate the structure of QSG, NMR analysis was conducted. The ${ }^{13} \mathrm{C}$ NMR spectrum of this gum indicated it has a highly branched structure. The spectrum of QSG contained the signals corresponded to $(1 \rightarrow 4) \rightarrow \beta$-D-Xyl $p,(1 \rightarrow 4)-\beta$-D-Xyl $p$-2-o-Glc $p$ A, and 4-oMe- $\alpha$-D-Glc $p$ (Table 2). The resonance for carbonyl groups of the terminal non-reducing Dglucuronic acid was observed at $176.17 \mathrm{ppm}^{37}$. The anomeric region includes various glycoside linkages in polysaccharide structure. The peak observed at $97.52 \mathrm{ppm}$ is related to 4-o-Me- $\alpha$-DGlcp $(1 \leftarrow$ residues and the main one at $101.64 \mathrm{ppm}$ is due to $(1 \rightarrow 4)-\beta-\mathrm{D}-\mathrm{Xyl} p-2-\mathrm{o}-\mathrm{Glc} p \mathrm{~A}$. The peak at 104.19 is related to $(1 \rightarrow 4) \rightarrow \beta$-D-Xylp. Therefore, it can be suggested that QSG has a highly substituted xylan structure. Additionally, the signal at $109.53 \mathrm{ppm}$ and $62.21 \mathrm{ppm}$ arise from $\mathrm{C}-1$ and $\mathrm{C}-2$ of residual $\alpha$-L-Araf units.

(Fig. 2)

(Table 2)

\subsection{Analysis of macromolecular weight and its characteristics}

The molecular weight of a biopolymer is considered as an important parameter due to its effect on functional characteristics of polysaccharides ${ }^{38}$. Therefore, molecular properties of QSG were analyzed. GPC elution profile of QSG is depicted in Fig. 3. Weight average molecular weight of QSG $\left(9.61 \times 10^{6} \mathrm{~g} / \mathrm{mol}\right)$ was more when compared to commercial gums such as xanthan gum $\left(4.05 \times 10^{6} \mathrm{Da}\right)^{39}$, guar gum $\left(1.45 \times 10^{6} \mathrm{Da}\right)^{40}$, gellan gum $\left(1.64 \times 10^{6} \mathrm{Da}\right)^{41}$ and locust bean gum $\left(1.6 \times 10^{6} \mathrm{Da}\right)^{42}$. The molecular weight is a determinant factor for thickening and gelling properties of hydrocolloids. For example, xanthan has a molecular weight (4200 kDa) and as a result impart a high level of viscosity-enhancing property ${ }^{43,44}$. Therefore, QSG can be 
introduced as a good thickening agent because it has high molecular weight. Rheological properties of QSG will be discussed in the continuation of this research. Moreover, high molecular weight polysaccharide does not have much tendency to be adsorbed at the air-water interface, but they can profoundly reinforce the protein foams stability due to thickening or gelling characteristics ${ }^{45}$. Thus, QSG can be introduced as a good stabilizing agent in protein foams. Number average molecular weight $(\mathrm{Mn})$ of QSG $\left(4.153 \times 10^{6} \mathrm{~g} / \mathrm{mol}\right)$ was more when compared to most hydrocolloids that have been studied so far.

(Fig. 3)

\subsection{Rheological properties}

\subsubsection{Dilute solution properties}

Before intrinsic viscosity measurements, master curve (log $\eta_{\mathrm{sp}}$ against $\log \mathrm{C} \times$ intrinsic viscosity) was plotted to confirm that tested solutions are in a dilute domain. When the slope of the master curve is less than 1.4, it can be found that there are no coil overlaps. In a concentrated regime, the slope increase to $3.3^{46}$. The results indicated that slopes of master curves for QSG at salt concentration were in the range of 0.98 to 1.99 , exhibiting that QSG solutions were in the dilute domain without molecular entanglements.

Intrinsic viscosity is a property related to the hydrodynamic volume occupied by the polymer ${ }^{21}$. The high determination coefficient and low mean square error revealed that TanglertpaibulRao's equation might be adequate to estimate intrinsic viscosity of QSG (Fig. 4). This result is in line with those reported in previous studies ${ }^{23,46-49}$. The intrinsic viscosity of QSG was $16.96 \mathrm{dl} / \mathrm{g}$ (in deionized water at $\left.25^{\circ} \mathrm{C}\right)$ which was more than the data obtained for gum arabic $(0.6 \mathrm{dl} / \mathrm{g}$ at 
$\left.20^{\circ} \mathrm{C}\right)$ and guar gum $(9.25 \mathrm{dl} / \mathrm{g})$, and smaller than that estimated for Tragacanth gum $(19.2 \mathrm{dl} / \mathrm{g})$, 6

Following an increase in the ion concentration, the intrinsic viscosity of QSG decreased which is due to the shielding influence of charges on macromolecular chains ${ }^{50}$. With increasing the ion concentration, the impact of shielding of charges reinforced and consequently the molecular repulsions, followed by intrinsic viscosity diminished ${ }^{51}$. The similar results have been reported for sodium alginate ${ }^{52}$, Balangu seed gum ${ }^{51}$, xanthan ${ }^{14}$, Prunus armeniaca ${ }^{49}$ and hsiantsao leaf gum ${ }^{16}$.

Salt tolerance parameter is related to polymer chain stiffness. The less ionic strength dependency of intrinsic viscosity demonstrates a high level of chain flexibility ${ }^{19}$. The value of relative chain stiffness (B) of QSG in the presence of $\mathrm{CaCl}_{2}(0.24)$ was less than those of sage seed gum $(0.381)^{53}$ and Balangu seed gum $(0.346){ }^{51}$. Accordingly, QSG has a stiffer conformation in comparison to these biopolymers. On the other hand, the value obtained for B number was more than that of reported for rigid helices gum like xanthan $(0.00525)^{54}$.

(Table 3)

(Fig. 4)

\subsubsection{Steady shear behavior}

Hydrocolloids foods are occasionally processed under different environmental conditions such as mineralized solutions. Hence, the evaluation of salt addition influence on rheological properties of QSG is important to appointment mucilage function as a polyelectrolyte. The viscosity of 
charged macromolecules is considerably affected by ionic strength. In the absence of counter ions, a negative charge reinforces the electrostatic repulsion and as a result, produces a more expanded molecule. The results of the compositional analysis indicated that QSG had negatively charged polyelectrolyte molecules. Therefore, it is expectable that this gum can produce a high viscous solution in deionized water, because of high repulsive forces. The effect of $\mathrm{CaCL}_{2}$ addition on consistency coefficient of QSG solution is summarized in Table 3. The steady shear flow behavior of QSG solutions at all tested ion concentrations can be described by nonNewtonian profile characterized by a flow behavior index less than one. Following an increase in ionic strength from 0 to $50 \mathrm{mM}$, the consistency coefficient (as a measure of apparent viscosity) decreased. The reason for that may be related to decreasing in the electrostatic repulsion and molecules expansion which leads to a reduction inconsistency coefficient ${ }^{55}$. Furthermore, inorganic cations have a high degree of hydration and as a result of compactness of the hydrated layer around polyelectrolyte molecules. Therefore, an increase in ionic strength led to a decrease in consistency coefficient of solutions ${ }^{56}$. These observations are consistent with those of hsiantsao leaf gum ${ }^{57}$ and Opuntia ficus-indica gum ${ }^{55}$. Surprisingly, when the $\mathrm{CaCl}_{2}$ concentration increased from 100 to $500 \mathrm{mM}$, the magnitude of consistency coefficient increased from 12.21 to 14.88 Pa.s ${ }^{\mathrm{n}}$, indicating $\mathrm{CaCl}_{2}$ can reinforce the structural network of QSG. The experimental data of log apparent viscosity vs log shear rate is also presented as Fig. 5 which confirmed the effect of $\mathrm{CaCL}_{2}$ on steady shear behavior of QSG.

With increasing salt concentration from 0 to $50 \mathrm{mM}$, flow behavior index increased from 0.28 to 0.30 , indicating that hydrocolloid solutions tend to be lower shear thinning in the presence of salt. On the other hand, with further increasing of salt concentration, flow behavior index values 
decreased. This trend may be due to the reinforcement of electrostatic interaction between calcium ions and polymer macromolecules and as a result increasing molecular entanglements.

(Table 3)

(Fig. 5)

\subsubsection{Dynamic rheological behavior}

\subsubsection{Strain sweep measurements}

With increasing stain, two distinct domains namely linear viscoelastic region where $G^{\prime}$ and $G^{\prime \prime}$ were almost constant, and nonlinear region in which $\mathrm{G}^{\prime}$ and $\mathrm{G}^{\prime \prime}$ started to decrease were distinguished. In the strain sweep tests, $G^{\prime}$ remained constant until the strain reached a critical point at which G' started to decrease sharply, as demonstrated in Fig. 6-a. The strain at which G' decreased sharply is defined as the critical strain. Therefore, critical strain reflects the deformability of the gum ${ }^{58}$. Strong gum solutions maintain longer at linear state compared to weak gum solutions ${ }^{59}$; in other words, viscoelastic moduli can be linear in a wide strain range. The linear region for dilute solutions is less than concentrate solutions and this is less than gels. While the strain value at the limit of LVE rarely exceeds 0.1 for colloidal gels, a larger LVE region with a strain equal to or exceeds 1 is for natural biopolymer gels ${ }^{60}$.

(Fig. 6)

At low salt concentrations $(10-50 \mathrm{mM})$, the elastic modulus remained constant at strain up to about $20 \%$. With increasing in salt concentration, the strain at which the elastic modulus decreases, increased to more than $100 \%$. While in the absence of salt, elastic modulus remained stable at strain up to about 3\% (Table 3), which indicates that increasing salt concentration 
increased the strength of the system and got more rigid. The values of $G^{\prime}$ and $G^{\prime \prime}$ at LVE region also increased with increase in salt concentrations (Table 3). Increasing salt concentration from 10 to $500 \mathrm{mM}$ increased the structural strength ( $\mathrm{G}^{\prime}$ at LVE) of gum solution at constant concentration. It should be noted that, at low salt concentrations $(10-50 \mathrm{mM})$, compared to the absence of salt, the values of $\mathrm{G}^{\prime}$ and $\mathrm{G}^{\prime \prime}$ were decreased. This shows that at low concentrations of salt, structural strength (G' at LVE) of gum solution was weakened. This kind of experiment also reveals the upmost deformation that a system can tolerate without structural failure; in another word, determination of the critical strain as corresponding of the linear viscoelastic range is a yardstick of structural strength and shape maintenance factor versus the mechanical stresses ${ }^{58}$.The critical strain values for QSG were 3.7, 74.5, 75.1, 110.6 and $131.1 \%$ for $0,10,50,100$ and $500 \mathrm{mM}$ salt concentrations, respectively. At this point, G' diminished aggressively, which exhibits the strain that led to the first non-linear changes in the structure of aqueous gum dispersion.

\subsubsection{Frequency sweep measurements}

Frequency sweep data can be applied to determine or categorize dispersions. The four most ordinary and common classifications are that of a dilute solution, an entanglement network systems (or a concentrated solution), a weak gel and a strong gel ${ }^{60}$. Fig 6-b shows the frequency dependence of $\mathrm{G}^{\prime}$ for $\mathrm{QSG}$ in the presence of $\mathrm{Ca}^{2+}$ ions at ambient temperature. At any concentration of $\mathrm{CaCl}_{2}$ from $0 \mathrm{mM}$ to $500 \mathrm{mM}, \mathrm{G}^{\prime}$ was larger than $\mathrm{G}^{\prime \prime}$ (Data not shown), and both moduli were only slightly frequency dependent throughout the accessible frequency range.

This behavior is classified rheologically as that of a weak gel ${ }^{61,62}$. Therefore, the gel-like 
behavior was observed at all various concentrations of $\mathrm{CaCl}_{2}$. According to Martínez-Ruvalcaba, Chornet and Rodrigue ${ }^{63}$, in weak gels, both moduli display light frequency dependency, with $\mathrm{G}^{\prime}$ exceeding $\mathrm{G}^{\prime \prime}$ at all frequencies. However, $\mathrm{G}^{\prime}$ and $\mathrm{G}^{\prime \prime}$ values for 10 and $50 \mathrm{mM} \mathrm{\textrm {CaCl } _ { 2 }}$ concentrations were lower than that of the blank sample without salt (Fig. 6), showing that the elastic properties can be decreased at the special concentration. This result is consistent with that observed in steady shear behavior.

\section{Conclusion}

QSG is a high molecular weight polysaccharide contains $6.39 \%$ arabinose, $40.43 \%$ xylose, $5.60 \%$ galactose, $5.75 \%$ glucose and $31.11 \%$ mannose. By using FT-IR and ${ }^{13} \mathrm{CNMR}$ analysis, the characteristics of functional groups and structural properties of QSG were identified. The results of monosaccharide composition and ${ }^{13} \mathrm{C}$ NMR analysis showed that the structural makeup of this gum could consist of xylan and/or mannan backbone with the branching of arabinose, galactose, and glucose. FT-IR analysis indicated the presence of carboxyl group, which can 
improve rheological properties of QSG. The dilute solution behavior of QSG in the presence of $\mathrm{CaCl}_{2}$ was evaluated.The value of salt tolerance parameter of QSG exhibited that this gum has a stiff conformation. Based on the steady and dynamic behavior of QSG, it was found that rheological properties of this gum improved in the special concentration of $\mathrm{CaCl}_{2}$.

\section{References}

1. Fathi M, Mohebbi $\mathrm{M}$ and Koocheki A, Introducing Prunus cerasus gum exudates: Chemical structure, molecular weight, and rheological properties. Food Hydrocolloids (2016).

2. Cheng Y, Brown KM and Prud'homme RK, Preparation and characterization of molecular weight fractions of guar galactomannans using acid and enzymatic hydrolysis. International Journal of Biological Macromolecules 31:29-35 (2002). 
3. Trigueros L, Pérez-Alvarez J, Viuda-Martos M and Sendra E, Production of low-fat yogurt with quince (Cydonia oblonga Mill.) scalding water. LWT-Food Science and Technology 44:1388-1395 (2011).

4. Jouki M, Mortazavi SA, Yazdi FT and Koocheki A, Optimization of extraction, antioxidant activity and functional properties of quince seed mucilage by RSM. International journal of biological macromolecules 66:113-124 (2014).

5. Abbastabar B, Azizi MH, Adnani A and Abbasi S, Determining and modeling rheological characteristics of quince seed gum. Food Hydrocolloids 43:259-264 (2015).

\section{6. (!!! INVALID CITATION !!!).}

7. Firestone D, Official methods of analysis of the Association of Official Analytical Chemists. Arlington, USA (1990).

8. Blumenkrantz $\mathrm{N}$ and Asboe-Hansen $\mathrm{G}$, New method for quantitative determination of uronic acids. Analytical biochemistry 54:484-489 (1973).

9. Arnous A and Meyer AS, Quantitative prediction of cell wall polysaccharide composition in grape (Vitis vinifera L.) and apple (Malus domestica) skins from acid hydrolysis monosaccharide profiles. Journal of agricultural and food chemistry 57:3611-3619 (2009).

10. Lima ÉC, Barbosa Jr F, Krug FJ and Tavares A, Copper determination in biological materials by ETAAS using W-Rh permanent modifier. Talanta 57:177-186 (2002).

11. Kraemer EO, Molecular weights of celluloses and cellulose derivates. Industrial \& Engineering Chemistry 30:1200-1203 (1938).

12. Huggins ML, The viscosity of dilute solutions of long-chain molecules. IV. Dependence on concentration. Journal of the American Chemical Society 64:2716-2718 (1942). 
13. Tanglertpaibul $\mathrm{T}$ and Rao $\mathrm{M}$, Intrinsic viscosity of tomato serum as affected by methods of determination and methods of processing concentrates. Journal of Food Science 52:1642-1645 (1987).

14. Higiro J, Herald $\mathrm{T}$ and Alavi S, Rheological study of xanthan and locust bean gum interaction in dilute solution. Food Research International 39:165-175 (2006).

15. Higiro J, Herald T, Alavi S and Bean S, Rheological study of xanthan and locust bean gum interaction in dilute solution: Effect of salt. Food Research International 40:435-447 (2007).

16. Lai L, Tung J and Lin P, Solution properties of hsian-tsao (Mesona procumbens Hemsl) leaf gum. Food Hydrocolloids 14:287-294 (2000).

17. Lai L-S and Chiang H-F, Rheology of decolorized hsian-tsao leaf gum in the dilute domain. Food hydrocolloids 16:427-440 (2002).

18. Smidsrød O and Haug A, Estimation of the relative stiffness of the molecular chain in polyelectrolytes from measurements of viscosity at different ionic strengths. Biopolymers 10:1213-1227 (1971).

19. Lapasin R and Pricl S, Rheology of polysaccharide systems, in Rheology of industrial polysaccharides: Theory and applications. Springer, pp 250-494 (1995).

20. Fekri N, Khayami M, Heidari R and Jamee R, Chemical analysis of flaxseed, sweet basil, dragon head and quince seed mucilages. Res J Biol Sci 3:166-170 (2008).

21. Cui W and Mazza G, Physicochemical characteristics of flaxseed gum. Food Research International 29:397-402 (1996). 
22. Dakia PA, Blecker C, Robert C, Wathelet B and Paquot M, Composition and physicochemical properties of locust bean gum extracted from whole seeds by acid or water dehulling pre-treatment. Food Hydrocolloids 22:807-818 (2008).

23. Sherahi MH, Fathi M, Zhandari F, Hashemi SMB and Rashidi A, Structural characterization and physicochemical properties of Descurainia sophia seed gum. Food Hydrocolloids 66:82-89 (2017).

24. Fathi M, Mohebbi M and Koocheki A, Some physico-chemical properties of Prunus armeniaca L. gum exudates. International journal of biological macromolecules 82:744-750 (2016).

25. Pachuau L, Lalhlenmawia $\mathrm{H}$ and Mazumder B, Characteristics and composition of Albizia procera (Roxb.) Benth gum. Industrial Crops and Products 40:90-95 (2012).

26. Cui SW, Phillips GO, Blackwell B and Nikiforuk J, Characterisation and properties of Acacia senegal (L.) Willd. var. senegal with enhanced properties (Acacia (sen) SUPERGUM ${ }^{\mathrm{TM}}$ ): Part 4. Spectroscopic characterisation of Acacia senegal var. senegal and Acacia (sen) SUPERGUM ${ }^{\mathrm{TM}}$ arabic. Food hydrocolloids 21:347-352 (2007).

27. Vanloot P, Dupuy N, Guiliano M and Artaud J, Characterisation and authentication of A. senegal and A. seyal exudates by infrared spectroscopy and chemometrics. Food chemistry 135:2554-2560 (2012).

28. Guiliano M, Asia L, Chatel S and Artaud J, Contribution of infrared spectroscopy to rapid analysis of polysaccharidic texturing agents. Annales des Falsifications de l'Expertise Chimique et Toxicologique (France) (2002).

29. Khondka P, Composition and partial structure characterization of Tremella polysaccharides. Mycobiology 37:286-294 (2009). 
30. Percival EGV and Percival E, Structural carbohydrate chemistry. (1962).

31. Anvari M, Tabarsa M, Cao R, You S, Joyner HS, Behnam S and Rezaei M, Compositional characterization and rheological properties of an anionic gum from Alyssum homolocarpum seeds. Food Hydrocolloids 52:766-773 (2016).

32. Rath R, Subramanian S, Sivanandam V and Pradeep T, Studies on the interaction of guar gum with chalcopyrite. Canadian metallurgical quarterly (2013).

33. Kacurakova M, Capek P, Sasinkova V, Wellner N and Ebringerova A, FT-IR study of plant cell wall model compounds: pectic polysaccharides and hemicelluloses. Carbohydrate polymers 43:195-203 (2000).

34. Yuen S-N, Choi S-M, Phillips DL and Ma C-Y, Raman and FTIR spectroscopic study of carboxymethylated non-starch polysaccharides. Food Chemistry 114:1091-1098 (2009).

35. Silverstein RM, Webster FX, Kiemle DJ and Bryce DL, Spectrometric identification of organic compounds. John Wiley \& Sons (2014).

36. Sharma VK and Mazumdar B, Feasibility and characterization of gummy exudate of Cochlospermum religiosum as pharmaceutical excipient. Industrial Crops and Products 50:776786 (2013).

37. de Pinto GL, Martínez M and Rivas C, Chemical and spectroscopic studies of Cercidium praecox gum exudate. Carbohydrate research 260:17-25 (1994).

38. Yang B, Jiang Y, Zhao M, Shi J and Wang L, Effects of ultrasonic extraction on the physical and chemical properties of polysaccharides from longan fruit pericarp. Polymer Degradation and Stability 93:268-272 (2008). 
39. Viturawong Y, Achayuthakan P and Suphantharika M, Gelatinization and rheological properties of rice starch/xanthan mixtures: Effects of molecular weight of xanthan and different salts. Food Chemistry 111:106-114 (2008).

40. Khouryieh H, Herald $\mathrm{T}$, Aramouni $\mathrm{F}$ and Alavi S, Intrinsic viscosity and viscoelastic properties of xanthan/guar mixtures in dilute solutions: Effect of salt concentration on the polymer interactions. Food Research International 40:883-893 (2007).

41. Sworn G and Kasapis S, Effect of conformation and molecular weight of co-solute on the mechanical properties of gellan gum gels. Food Hydrocolloids 12:283-290 (1998).

42. Doublier J and Launay B, Rheology of galactomannan solutions: comparative study of guar gum and locust bean gum. Journal of Texture Studies 12:151-172 (1981).

43. Faria S, de Oliveira Petkowicz CL, de Morais SAL, Terrones MGH, de Resende MM, de França FP and Cardoso VL, Characterization of xanthan gum produced from sugar cane broth. Carbohydrate Polymers 86:469-476 (2011).

44. Harding SE and Adams GG, An introduction to polysaccharide biotechnology. CRC Press (2002).

45. Martinez K, Baeza R, Millan F and Pilosof A, Effect of limited hydrolysis of sunflower protein on the interactions with polysaccharides in foams. Food Hydrocolloids 19:361-369 (2005).

46. Morris ER, Cutler A, Ross-Murphy S, Rees D and Price J, Concentration and shear rate dependence of viscosity in random coil polysaccharide solutions. Carbohydrate polymers 1:5-21 (1981). 
47. Antoniou E, Themistou E, Sarkar B, Tsianou M and Alexandridis P, Structure and dynamics of dextran in binary mixtures of a good and a bad solvent. Colloid and Polymer Science 288:1301-1312 (2010).

48. McMillan DE, A comparison of five methods for obtaining the intrinsic viscosity of bovine serum albumin. Biopolymers 13:1367-1376 (1974).

49. Fathi M, Mohebbi M, Koocheki A and Hesarinejad MA, Dilute solution properties of Prunus armeniaca gum exudates: Influence of temperature, salt, and sugar. International journal of biological macromolecules 96:501-506 (2017).

50. Draget KI, Moe S, Skjåk-Bræk G, Alginates Smidsrød O, Stephen A, Phillips G and Williams P, Food polysaccharides and their applications, Ed. CRC Press, Boca Raton (2006).

51. Amini AM and Razavi SM, Dilute solution properties of Balangu (Lallemantia royleana) seed gum: Effect of temperature, salt, and sugar. International Journal of Biological Macromolecules 51:235-243 (2012).

52. Pamies R, Cifre JGH, Martínez MdCL and de la Torre JG, Determination of intrinsic viscosities of macromolecules and nanoparticles. Comparison of single-point and dilution procedures. Colloid and Polymer Science 286:1223-1231 (2008).

53. Yousefi A, Razavi SM and Aghdam SK, Influence of temperature, mono-and divalent cations on dilute solution properties of sage seed gum. International journal of biological macromolecules 67:246-253 (2014).

54. Tinland B and Rinaudo M, Dependence of the stiffness of the xanthan chain on the external salt concentration. Macromolecules 22:1863-1865 (1989). 
55. Medina-Torres L, Brito-De La Fuente E, Torrestiana-Sanchez B and Katthain R, Rheological properties of the mucilage gum (Opuntia ficus indica). Food hydrocolloids 14:417424 (2000).

56. $\mathrm{Xu} \mathrm{L}$, Gong H, Dong M and Li Y, Rheological properties and thickening mechanism of aqueous diutan gum solution: Effects of temperature and salts. Carbohydrate polymers 132:620629 (2015).

57. Lin H-Y and Lai L-S, Isolation and viscometric characterization of hydrocolloids from mulberry (Morus alba L.) leaves. Food Hydrocolloids 23:840-848 (2009).

58. Hesarinejad MA, Koocheki A and Razavi SMA, Dynamic rheological properties of Lepidium perfoliatum seed gum: Effect of concentration, temperature and heating/cooling rate. Food Hydrocolloids 35:583-589 (2014).

59. Steffe JF, Rheological methods in food process engineering. Freeman press (1996).

60. Clark AH and Ross-Murphy SB, Structural and mechanical properties of biopolymer gels, in Biopolymers. Springer, pp 57-192 (1987).

61. Te Nijenhuis K, Viscoelastic properties of thermoreversible gels. Physical networks: Polymers and gels:15-33 (1990).

62. Ross-Murphy SB, Structure-property relationships in food biopolymer gels and solutions. Journal of Rheology 39:1451-1463 (1995).

63. Martínez-Ruvalcaba A, Chornet E and Rodrigue D, Viscoelastic properties of dispersed chitosan/xanthan hydrogels. Carbohydrate Polymers 67:586-595 (2007).

\section{Acknowledgements}


This work has been financially supported by Fasa University.

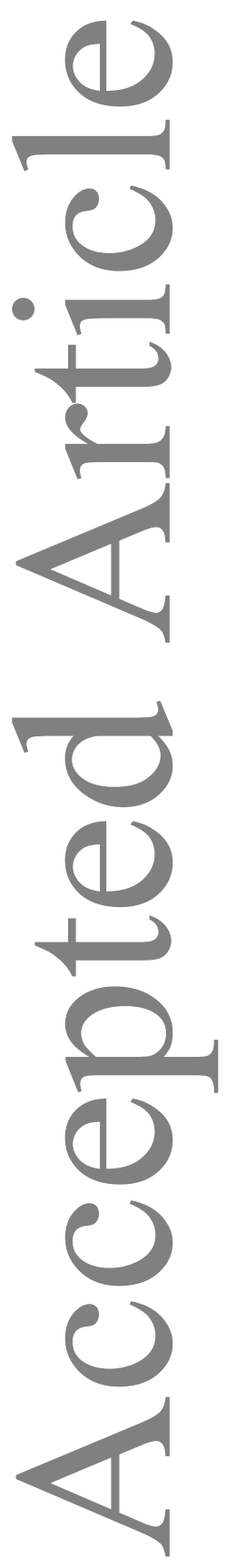


Table 1. Chemical composition of QSG*

\begin{tabular}{|c|c|c|}
\hline Composition (\%) & & $\mathrm{QSG}^{*}$ \\
\hline \multirow{10}{*}{$\begin{array}{l}\text { Carbohydrate } \\
\text { Monosaccharide }\end{array}$} & & $85.04 \pm 2.87$ \\
\hline & & \\
\hline & L-Arabinose & $6.39 \pm 0.18$ \\
\hline & Rhamnose & $<\mathrm{MDL}^{* *}$ \\
\hline & D-Xylose & $40.43 \pm 0.47$ \\
\hline & D-Galactose & $5.60 \pm 0.08$ \\
\hline & D-Glucose & $5.75 \pm 0.08$ \\
\hline & D-Mannose & $31.11 \pm 0.48$ \\
\hline & Galacturonic acid & $0.81 \pm 0.08$ \\
\hline & Glucuronic acid & $8.54 \pm 0.20$ \\
\hline Uronic acid & & $13.16 \pm 1.73$ \\
\hline Protein & & $2.78 \pm 0.21$ \\
\hline Moisture & & $5.77 \pm 0.83$ \\
\hline Fat & & $0.75 \pm 0.11$ \\
\hline Ash & & $5.64 \pm 0.48$ \\
\hline \multirow[t]{13}{*}{ Elements (ppm) } & & \\
\hline & Calcium $(\mathrm{Ca})$ & $7333.1 \pm 1.32$ \\
\hline & Magnesium (Mg) & $2632.8 \pm 2.21$ \\
\hline & Manganese (Mn) & $11.2 \pm 0.21$ \\
\hline & Potassium (K) & $74.12 \pm 1.40$ \\
\hline & $\operatorname{Zinc}(\mathrm{Zn})$ & $96.03 \pm 2.00$ \\
\hline & Cobalt (Co) & $<\mathrm{MDL}$ \\
\hline & Copper $(\mathrm{Cu})$ & $2.01 \pm 0.08$ \\
\hline & Aluminum (Al) & $2.28 \pm 0.44$ \\
\hline & Nickel (Ni) & $0.06 \pm 0.01$ \\
\hline & Lead $(\mathrm{Pb})$ & $<\mathrm{MDL}$ \\
\hline & Cadmium (Cd) & $<\mathrm{MDL}$ \\
\hline & Arsenic (As) & $<\mathrm{MDL}$ \\
\hline
\end{tabular}

*Values are means \pm SD of triplicate determination

**MDL: Method detection limits 
Table $2 .{ }^{13} \mathrm{C}$ signals of QSG. Chemical shift is expressed in ppm.

\begin{tabular}{|c|c|c|c|c|c|c|c|}
\hline Residue & $\mathrm{C}-1$ & $\mathrm{C}-2$ & $\mathrm{C}-3$ & $\mathrm{C}-4$ & $\mathrm{C}-5$ & $\mathrm{C}-6$ & $\mathrm{O}-\mathrm{CH}_{3}$ \\
\hline$(1 \rightarrow 4) \rightarrow \beta-\mathrm{D}-\mathrm{Xyl} p$ & 104.79 & 72.27 & 71.94 & 73.47 & 6.21 & - & - \\
\hline $\begin{array}{l}(1 \rightarrow 4)-\beta-\mathrm{D}-\mathrm{Xyl} p-2-\mathrm{o}- \\
\text { Glc } p \mathrm{~A}\end{array}$ & 101.64 & 75.11 & 71.02 & 73.17 & 62.16 & - & - \\
\hline 4-o-Me- $\alpha-\mathrm{D}-\mathrm{Glc} p$ & 97.52 & 70.67 & 75.26 & 81.49 & 71.26 & 176.17 & 59.29 \\
\hline
\end{tabular}
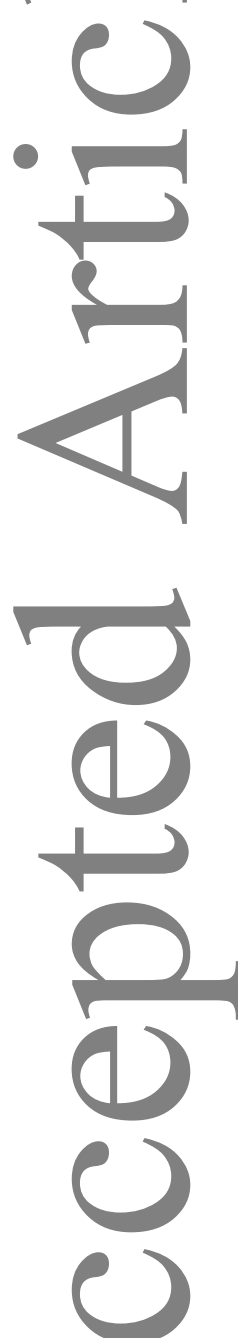
Table 3. The effect of ionic strength on steady shear parameters of QSG solutions $\left(0.5 \%\right.$, at $\left.25{ }^{\circ} \mathrm{C}\right)$ and viscoelastic properties (quantified by strain sweep experiments at frequency of $1 \mathrm{~Hz}$ ).

\begin{tabular}{|c|c|c|c|c|}
\hline Steady shear test & $\mathrm{k}\left(\mathrm{Pa} \mathrm{s}^{\mathrm{n}}\right)$ & n (-) & $\mathrm{R}^{2}$ & RMSE \\
\hline \multicolumn{5}{|l|}{$\mathrm{CaCl}_{2}(\mathrm{mM})$} \\
\hline 0 & $7.62 \pm 0.44^{\mathrm{c}}$ & $0.28 \pm 0.00^{\mathrm{ab}}$ & 0.999 & 0.000 \\
\hline 10 & $6.11 \pm 0.33^{\mathrm{d}}$ & $0.29 \pm 0.01^{\mathrm{a}}$ & 0.999 & 0.003 \\
\hline 50 & $6.01 \pm 0.23^{\mathrm{cd}}$ & $0.30 \pm 0.01^{\mathrm{a}}$ & 0.998 & 0.009 \\
\hline 100 & $12.21 \pm 0.18^{\mathrm{b}}$ & $0.21 \pm 0.01^{\mathrm{c}}$ & 0.998 & 0.011 \\
\hline 500 & $14.88 \pm 0.96^{\mathrm{a}}$ & $0.20 \pm 0.02^{\mathrm{c}}$ & 0.994 & 0.012 \\
\hline Strain sweep test & $\mathrm{G}_{\text {LVR }}^{\prime}(\mathrm{Pa})$ & G” ${ }_{\text {LVR }}(\mathrm{Pa})$ & $y_{L V R}(\%)$ & Tan $\delta_{\text {LVR }}$ \\
\hline 0 & $15.01 \pm 0.26^{\mathrm{a}}$ & $6.94 \pm 0.19^{\mathrm{a}}$ & $3.7 \pm 0.35^{\mathrm{d}}$ & $0.46 \pm 0.01^{\mathrm{b}}$ \\
\hline 10 & $4.97 \pm 0.67^{\mathrm{d}}$ & $2.62 \pm 0.14^{\mathrm{b}}$ & $74.5 \pm 1.18^{\mathrm{c}}$ & $0.53 \pm 0.01^{\mathrm{a}}$ \\
\hline 50 & $5.10 \pm 0.56^{\mathrm{d}}$ & $2.16 \pm 0.23^{\mathrm{e}}$ & $75.1 \pm 4.17^{\mathrm{c}}$ & $0.42 \pm 0.02^{\mathrm{c}}$ \\
\hline 100 & $12.69 \pm 0.23^{\mathrm{c}}$ & $3.77 \pm 0.11^{\mathrm{d}}$ & $110.6 \pm 3.12^{\mathrm{b}}$ & $0.29 \pm 0.01^{\mathrm{d}}$ \\
\hline 500 & $14.32 \pm 0.22^{\mathrm{b}}$ & $4.36 \pm 0.22^{\mathrm{c}}$ & $131.1 \pm 6.14^{\mathrm{a}}$ & $0.30 \pm 0.02^{\mathrm{d}}$ \\
\hline
\end{tabular}

a, b, c, d, and e Different letters in the same column indicate significant differences at 5\%. 


\section{Figures caption}

Fig. 1 FT-IR spectrum of QSG.

Fig. 2. ${ }^{13} \mathrm{C}$ NMR spectrum of QSG.

Fig. 3 Molecular properties of QSG.

Fig. 4 The plot of relative viscosity against solution concentration

Fig.5 The experimental data of log apparent viscosity vs log shear rate

Fig. 6 Changes of storage modulus in strain sweep (a) and frequency sweep (b) tests at various ion concentrations. 


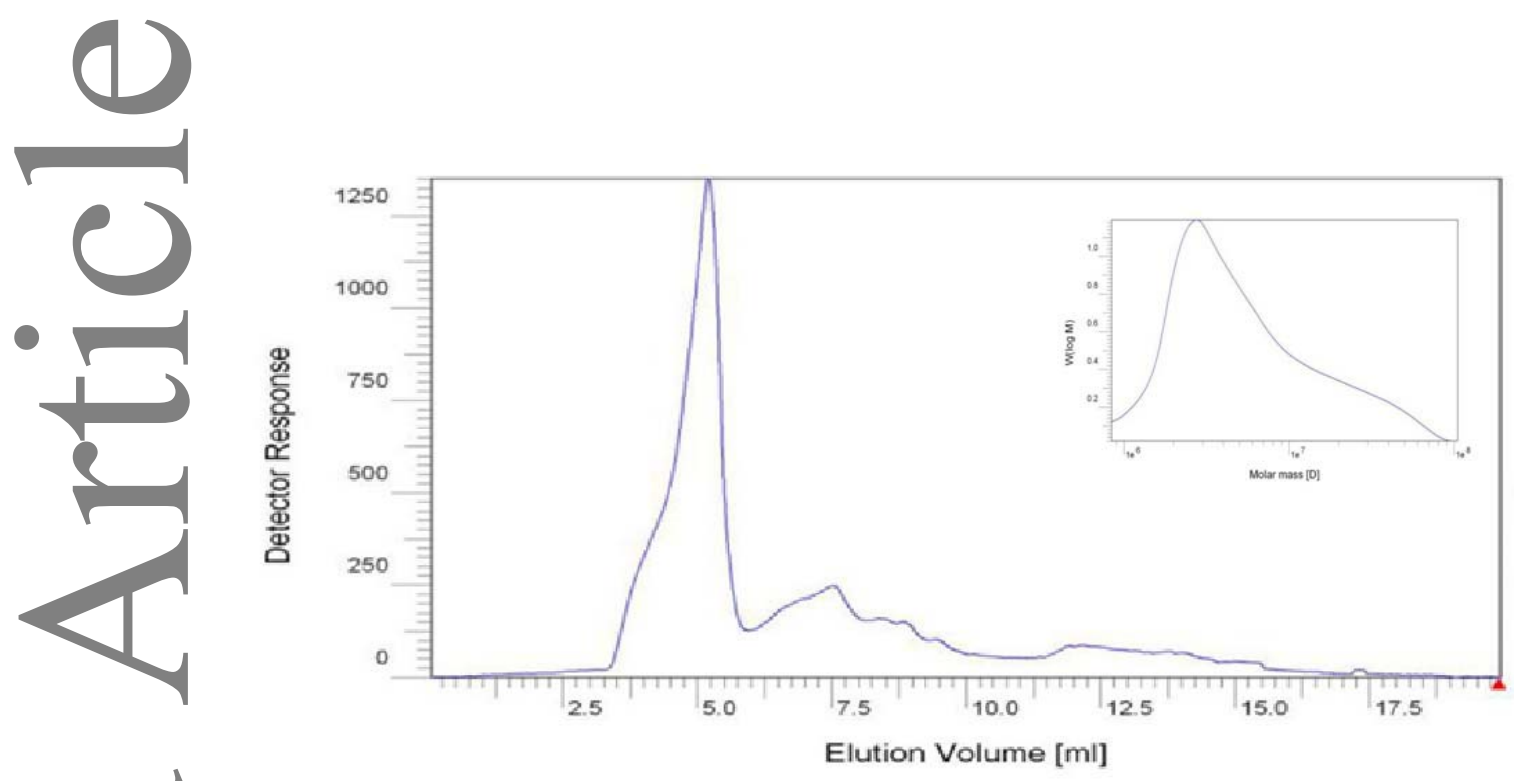

Fig. 3 


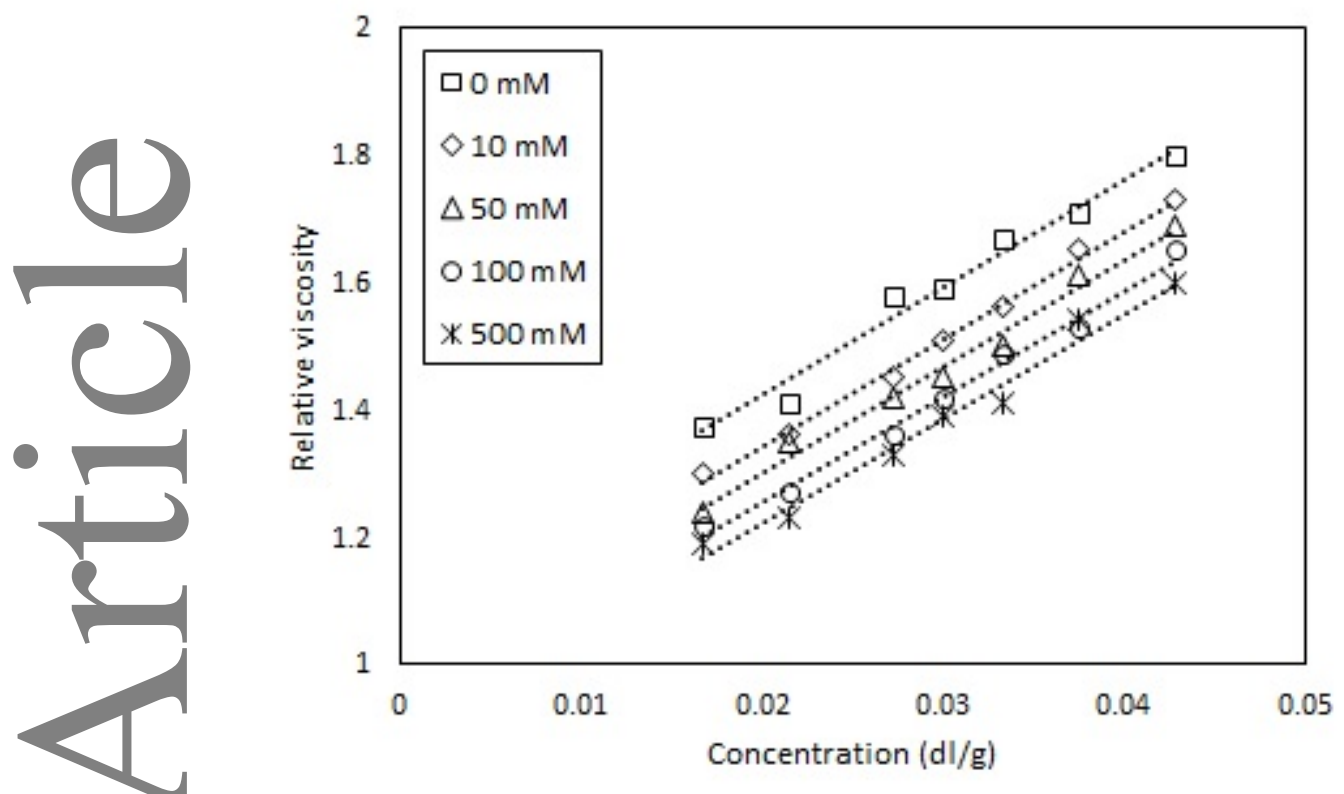

Fig. 4 
